\title{
Offspring at High and Low Risk for Depression and Anxiety: Mechanisms of Psychiatric Disorder
}

\author{
VIRGINIA WARNER, M.P.H., LAURA MUFSON, Ph.D., AND MYRNA M. WEISSMAN, Ph.D.
}

\begin{abstract}
Objectives: To examine the effect of parental psychiatric diagnosis on the risk of psychiatric disorder in their offspring and to determine mediators and independent predictors of psychiatric disorder in offspring. Method: The sample consisted of 145 offspring (between the ages of 6 and 24 years, who were directly interviewed) of probands with earlyonset (before age 30 years) major depressive disorder (MDD) without panic, panic disorder with and without major depression, and a normal, never psychiatrically ill control group who were part of a large study conducted to determine the relationship between panic disorder and major depression. Results: The risk for offspring MDD was increased by proband recurrent early-onset MDD and coparent alcohol abuse. Chaotic family environment was the only independent predictor of dysthymia. The risk for offspring "any anxiety" disorder was increased by proband recurrent early-onset MDD and coparent impaired functioning. The association between MDD in proband and "panic spectrum" disorder in offspring was accounted for by chaotic family environment. Conclusion: Recurrent parental MDD has consistently been shown to be a strong risk factor for offspring MDD. Family environment plays an important role in low-level anxiety symptoms and dysthymia. Clinicians treating adults should be alert to risk factors for their offspring and to appropriate targets for early intervention. J. Am. Acad. Child Adolesc. Psychiatry, 1995, 34, 6:786-797. Key Words: depression, anxiety, environment, family.
\end{abstract}

The association between parental psychiatric disorder and psychiatric disorder in their offspring has been well documented. Offspring of parents with major depressive disorder (MDD) are at increased risk for major depression (Hammen et al., 1990a; Keller et al., 1988; Orvaschel, 1990; Weissman et al., 1987, 1988) and other problems as well (Keller et al., 1986; Weissman et al., 1986). Recurrent and/or early-onset MDD in the parent has in particular been shown to be a strong predictor of an increased risk for offspring MDD

\footnotetext{
Accepted October 18, 1994 .

Ms. Warner is Research Scientist, New York State Psychiatric Institute. Dr. Mufson is Assistant Professor of Clinical Psychology, Columbia University College of Physicians and Surgeons, and Research Scientist, New York State Psychiatric Institute. Dr. Weissman is Professor of Epidemiology in Psychiatry, Columbia University College of Physicians and Surgeons, and Director, Division of Clinical and Genetic Epidemiology, New York State Psychiatric Institute.

This research was supported by NIMH grants MH28274 and MH3619712. The authors acknowledge Chantal Caron, M.D., and Carl Anderson, M.D., who did the child and adolescent best-estimate diagnoses; Priya Wickramaratne, Ph.D., for her comments; and Susan Rotgard for her careful editing of the manuscript.

Reprint requests to Ms. Warner, NYSPI, Unit 14, 722 West 168th Street, New York, NY 10032; telephone: (212) 960-5859.

0890-8567/95/3406-0786\$03.00/0@1995 by the American Academy of Child and Adolescent Psychiatry.
}

(Keller et al., 1986; Kupfer et al., 1989; Orvaschel, 1990; Orvaschel et al., 1988; Weissman et al., 1984, 1988). Weissman et al. (1988), in a study of offspring (6 to 24 years of age) at high and low risk for MDD, found offspring of probands with onset of MDD before the age of 20 had significantly higher rates of MDD and an earlier age at onset of MDD than offspring of probands with later onset of MDD.

Likewise, offspring of parents with anxiety disorders (in particular, panic) are more inhibited and at increased risk for anxiety disorders (Bernstein et al., 1991; Biederman et al., 1990, 1991; Breslau et al., 1987; Casat, 1988; Crowe et al., 1983; Hopper et al., 1987; Kovacs et al., 1989; Last et al., 1987a,b, 1991; Last and Strauss, 1989; Moreau et al., 1989; Mufson et al., 1992; Rosenbaum et al., 1988; Silverman et al., 1988; Turner et al., 1987; Van der Molen et al., 1989; Weissman et al., 1984). In two separate studies of the same sample (one with only family history data on the offspring at the first interview and with direct interview data at follow-up conducted several years later) found conflicting evidence regarding the association between separation anxiety in the offspring and panic disorder in the proband (Mufson et al., 1992; 
Weissman et al., 1984). The family history study found a clear association between separation anxiety in the offspring and MDD and panic in the proband, while the study using direct interview data failed to replicate the earlier findings (Mufson et al., 1992; Weissman et al., 1984). However, in both studies there was not a group of probands with panic disorder without MDD so it was not possible to determine whether the effect on offspring psychiatric diagnosis was due to parental MDD or due to parental panic disorder.

Results from most studies suggest that parental diagnosis has both direct and indirect effects on disorder in offspring. Few studies have examined the possible mediators of the indirect effects of parental disorder (Hammen et al., 1988; Kendler et al., 1993; Reinherz et al., 1989). The work that has been done suggests that psychiatric disorders and the etiologies of psychiatric disorders are extremely complex and heterogeneous (Kendler et al., 1993; Lewinsohn et al., 1994; PuigAntich et al., 1993; Rutter, 1988; Weissman et al., 1993). It is also clear that risk factors for psychiatric disorders in offspring often do not operate individually and need to be considered in combination (Hammen et al., 1990b). Most studies do not examine risk factors in combination because of design and sample limitations. Few studies have looked at the effect of family environmental factors and both parents' diagnostic status simultaneously (Hammen et al., 1987). The Hammen et al. (1987) study of children of depressed mothers included a comprehensive list of risk factors. However, the data on the fathers were available only through family history, which has been found consistently to underestimate the rate of disorder.

The purpose of this article is (1) to examine the effect of MDD and/or panic disorder in probands on the risk of MDD and anxiety disorders in their offspring, and (2) to examine other factors (i.e., family environmental factors, coparent [i.e., spouse of proband] diagnoses, social adjustment) as possible mediators of that risk and as independent predictors of an increased risk for offspring MDD and anxiety disorder. Included in these goals are the attempt (1) to replicate previous findings regarding the transmission of earlyonset MDD from proband to offspring and separation anxiety as a precursor of panic disorder, (2) to examine the effects of recurrent MDD compared with nonrecurrent MDD on the risk for MDD and anxiety disorder in offspring, and (3) to test for the presence of panic symptoms in children and adolescents.

\section{METHOD}

The overall purpose of the original study was to obtain comprehensive data by direct interview and family history from multiple informants (and medical records when available) on the first-degree relatives of probands with early-onset (before age 30 years) MDD without panic, panic disorder with and without major depression, and a normal, never psychiatrically ill control group to determine the relationship between panic disorder and major depression. None of the probands, coparents, or adult telatives described here have been part of our earlier published family studies. All probands were directly interviewed and $70 \%$ of the offspring had coparents who were directly interviewed. Fifty-four percent of those coparents with only family history had two or more family history reports. A complete description of the probands, coparents, and relatives and their assessments and methods can be found elsewhere (Weissman et al., 1993). In this article we only report data on offspring aged 6 to 24 years in order to compare these results with earlier findings (Weissman et al., 1986, 1987).

\section{Offspring Assessments}

Interviews with offspring aged 6 to 17 years were based on the Schedule for Affective Disorders and Schizophrenia for SchoolAge Children-Epidemiologic Version (K-SADS-E) (Orvaschel et al., 1982). Offspring older than 17 years of age were interviewed with a modified version of the Schedule for Affective Disorders and Schizophrenia-Lifetime Version (SADS-L) (modified for the study of anxiety disorders) (Mannuzza et al., 1986). We attempted to interview directly all offspring 6 to 24 years of age. The parent was interviewed about the offspring only if the offspring was between the ages of 6 and 10 years. If the offspring was 11 to 17 years of age, the parent completed an abbreviated version of the interview package containing only the questions about family demographics, the offspring's general medical and neuropsychiatric history, and the offspring's use of neuropsychiatric medications. Questions about social adjustment included in the Social Adjustment Inventory for Children and Adolescents (John et al., 1987), developmental history of the offspring, and perception of family functioning were also asked and offspring were given the Peabody Picture Vocabulary Test (Dunn and Dunn, 1981). One hundred ten families in the sample had 209 offspring between the ages of 6 and 24 years. Eighty-two families had 145 offspring (69\%) who were interviewed with either the SADS-L or the K-SADS-E. Offspring who were not interviewed had data available through the family history method from multiple informants. Males and females were equally likely to be interviewed. Interviewed children were significantly younger than noninterviewed children (mean age of 14 years versus 16 years; $p=.06$ ). Interview status varied significantly by proband group $(p<.05)$. Seventy-six percent of the offspring of the never mentally ill probands, $82 \%$ of the offspring of the early-onset MDD probands, $54 \%$ of the offspring of panic without MDD probands, and $65 \%$ of the offspring of panic with MDD probands were interviewed. Offspring who were interviewed tended to be from families from a higher socioeconomic status (i.e., Hollingshead social classes I and II versus III, IV, V) than offspring who were not interviewed (38\% versus $21 \% ; p<$ $.05)$. For the purposes of this study, only the sample of interviewed offspring was used. 


\section{Interviewers}

The interviewers had master's degrees in social work, Ph.D. in clinical psychology, or were advanced clinical psychology Ph.D. students. Many had previous experience conducting interviews with children and had interviewed children in other family-genetic studies conducted by this group. They underwent training in the administration of the SADS-L and the K-SADS-E and the collection of pedigrees and family history. Training included 40 hours of lectures, small-group workshops, viewing of videotaped interviews, role-play practice, assigned homework, and supervised interviews. Interviewer meetings for monitoring were held weekly for the first 3 months, and monthly after training.

A test-retest study of the reliability of interviewers' diagnoses was conducted. Thirty-eight relatives from the family study were interviewed twice by different interviewers 4 to 10 days apart, using the SADS-L. Subjects were randomly selected and interviewers were assigned on the basis of availability. The agreement between interviewers $(N=10)$ on the presence or absence of diagnoses was fair for panic disorder $(\kappa=.66)$ and was excellent for MDD $(\kappa=.85)$.

\section{Diagnostic Criteria and Best-Estimate Diagnoses in Probands, Coparents, and Adult Relatives}

Because of the changing diagnostic criteria as well as our plans to compare results with our previous and other family studies, sufficient information was collected to make Axis I diagnoses according to Research Diagnostic Criteria, DSM-III criteria, and $D S M-I I I-R$ criteria for probands, coparents, and adult relatives. Best-estimate diagnoses were made on all available information on each proband, coparent, and adult relative (including adult offspring) and made separately by a psychiatrist or Ph.D.-level clinical psychologist who was blind to the proband status and was not involved in the data collection (Leckman et al., 1982). Diagnoses based on all available information were made by the three diagnostic systems and were made with variable levels of certainty: possible, probable, definite. Every case was reviewed by at least two M.D.or Ph.D.-level diagnosticians and, if there was no disagreement by any criteria or for any diagnosis, the best-estimate diagnosis was accepted. In cases where there was any disagreement, a consensus meeting was held and diagnosis was made with at least two diagnosticians.

\section{Offspring Diagnoses}

Only diagnoses according to DSM-III and DSM-III-R criteria were made for minor offspring (aged 6 to 17 years). Similar to the adult procedures, best-estimate diagnoses were made for all cases by two child psychiatrists. Both best-estimators were trained and achieved good to excellent reliability with senior best-estimators. Best-estimate diagnoses were made using all available information and blind to the proband's diagnostic status. If there was no disagreement between the two best-estimators, then the best estimate was accepted. If there was any disagreement between the estimators, then a consensus meeting was held. Agreement on diagnosis was calculated using the $\kappa$ statistic. The $K$ coefficients between each best estimate and consensus for MDD were $.75(n=$ $10)$ and $.93(n=10)$, respectively, and for any anxiety disorder $.93(n=24)$ and $.93(n=30)$, respectively. Agreement between the two best-estimators for MDD was fair. The $K$ for MDD was $.67(n=10)$ by both DSM-III and DSM-III-R criteria. It was not possible to determine $K$ scores for individual anxiety disorders because of the low base rates. Assessment of the offspring older than 17 years of age followed the same procedures as those described above for adult relatives.

\section{Offspring Outcomes}

Best-estimate DSM-III-R anxiety and depression diagnoses at the probable and definite level of certainty were used as the primary outcomes in offspring. Spontaneous, situational, and near panic attacks are diagnostic categories that attempt to capture subsyndromal panic that were arrived at as part of the development of the SADS-L modified for anxiety disorders (Mannuzza et al., 1986). Spontaneous panic attacks are unexpected or "out of the blue" and are not related to situational factors (Fyer et al., 1989). Situational panic attacks are those that occur in settings in which attacks sometimes but not always occur (Fyer et al., 1989). Near panic attacks are a partial syndrome of a spontaneous or situational attack (Fyer et al., 1989). Reliability studies conducted by Fyer et al. (1989) showed good/excellent reliability for spontaneous panic attacks $(\kappa=.90)$, good/excellent reliability for situational panic attacks $(\kappa=.63)$, and poor/fair reliability for near panic attacks $(\kappa=.47)$. "Any anxiety" includes the diagnoses of separation anxiety, near panic, spontaneous or situational panic attacks, social phobia, simple phobia, agoraphobia, panic disorder, obsessivecompulsive disorder, and overanxious disorder. Panic spectrum disorders include separation anxiety, near panic, isolated spontaneous or situational panic attacks, and panic disorder. Subsyndromal categories were included to capture partial syndromes that occur in childhood that may be precursors to adult panic and to examine whether children have or report spontaneous panic attacks.

\section{Predictors of Offspring DSM-III-R Diagnoses}

Proband and Coparent Characteristics. The proband diagnosis was looked at as a predictor. In addition to MDD and panic disorder, DSM-III-R alcohol abuse/dependence, drug abuse/dependence, and simple phobia were examined as predictors. Substance abuse disorders in the proband were examined as predictors because of their association with an increased risk for offspring MDD and anxiety disorders. Simple phobia in the proband was examined as a predictor because the rates of simple phobia varied by proband group. DSM-III-R MDD, anxiety disorders, and substance abuse disorders of the coparent were looked at as predictors.

Average lifetime functioning in the proband and coparent, as measured by the Global Assessment Scale (GAS) (Endicott et al., 1976), were also examined as predictors of offspring psychiatric disorder. The GAS has a range of 1 to 100 , with higher scores indicating better functioning. First the GAS was treated as a continuous variable and then as a dichotomous variable using a cutoff point of 61 . The results were the same for either method, so the dichotomous measure was used for greater interpretability.

Proband current social functioning was measured by the Social Adjustment Scale (Weissman et al., 1978), which measures social functioning in six role areas, i.e., work, spare time, marital, family, parenting, and children. The items are scored from 1 to 5 , with higher scores indicating more impairment in that area. Current functioning was looked at as a predictor.

Demographic Characteristics. Age and sex of offspring were looked at as predictors. Age was treated as a continuous measure. A 5-point scale based on the Hollingshead two-factor index of social position was used to measure socioeconomic status of the family (Hollingshead and Redlich, 1958). 
Family Environmental Factors Used as Predictors. A subset of 68 probands with 123 interviewed children filled out a battery of selfreport measures. The subset of probands who filled out the selfreport did not vary from the 14 probands (with interviewed children) who did not fill out the report on any diagnostic or demographic characteristic. Two such measures were used to assess the family environment: the Family Adaptability and Cohesion Scale (FACES) (Olson et al., 1979) and Dyadic Adjustment Scale (DAS), a measure of marital adjustment (Spanier, 1976). The FACES includes two subscales: the Adaptability subscale and the Cohesion subscale. Each subscale contains five items. The items are scored from 1 to 4. Low scores on the Cohesion subscale indicate low bonding and high autonomy. High scores on the Adaptability subscale (as suggested by Olson et al., 1979) indicate a chaotic family environment. Low cohesion scores would include responses such as "not very close to family members," "seldom spend time together," "always makes own decisions," "family members are independent" and "parents are seldom close." High scores on the Adaptability subscale would include responses such as "no clear leader," "family members seldom have the same roles," "rules seldom clear and change often in the family," "discipline of children is very lenient," and "family is seldom effective at solving problems." Probands with scores below the sample median on the Cohesion subscale were coded as 1 and above the median as 0 . Similarly, probands with scores above the median on the Adaptability subscale were coded as 1 and below the median as 0 . The DAS contains 32 items. The instrument consists of four subscales, i.e., Dyadic Consensus, Dyadic Satisfaction, Affectional Expression, and Dyadic Cohesion. The four subscales can be summed to create an overall score. For the purposes of this study, only the overall score was used. The DAS was trichotomized on the basis of the sample distribution. Low scores are indicative of having a marital problem and high scores indicate the absence of a marital problem. Analyses using the DAS as a continuous measure yielded the same results as using the trichotomized measure. A third measure of the family environment used was a history of divorce as reported by the proband.

\section{Statistical Methods}

Initially, the $\chi^{2}$ statistic was used to test associations between outcomes and predictor variables for categorical data (i.e., rates of offspring diagnoses by proband group, demographics, etc.) and the SAS GLM procedure for unbalanced analysis of variance for the continuous outcomes (i.e., age at onset of MDD by proband group) (SAS Institute, 1990). For interviewed offspring, where there were a sufficient number of cases of psychiatric disorder, the Cox multivariate proportional hazard model was used to assess the rates of psychiatric diagnoses in offspring by predictors (Cox, 1972). The proportional hazard model applies the multiple regression method to a survival distribution and yields a ratio of the hazards of the outcome variables (i.e., offspring diagnoses) for groups of interest. All predictors of offspring depression and anxiety disorder were looked at first individually, controlling for age and sex of the offspring, and then in combination in the model entering one predictor at a time. Proband diagnosis (i.e., early-onset MDD without panic, and panic with and without MDD) was looked at as a predictor of offspring depression and anxiety in analyses controlling for age and sex of offspring. Then, retaining proband diagnosis and the age and sex of offspring in the model, each additional predictor was added one at a time to assess whether that predictor acted as a mediator of the association between proband and offspring diagnosis or acted as an independent predictor. For each offspring outcome we examined whether recurrent early-onset MDD contributed more than nonrecurrent early-onset MDD to any increase in risk associated with early-onset MDD. In all models in which recurrent early-onset MDD was significant $(p<.05)$, we looked to see whether panic with recurrent, earlyonser MDD was a significant predictor. After the predictors were examined individually, we looked at them in combination. The size of the sample did not permit a formal statistical test for existing or probable interactions. However, we examined the bivariate associations between predictors and have reported the results where significant. The best model was identified by a highly significant model $\chi^{2}$ value; predictors were retained in the model if the change in the model $\chi^{2}$ when they were added was significant at the .05 level of significance; proband diagnosis and the age and sex of offspring were retained in all models; and care was taken to consider the significant associations between predictors.

\section{RESULTS}

\section{Demographics}

We found no significant differences in the age and sex distribution of the offspring by proband group. The mean age of the interviewed offspring was 14.5 years, and $40 \%$ were female. Probands with early-onset major depression or major depression with panic were significantly more likely to be females than probands from the never mentally ill or panic without MDD group (88\%, 83\%, 46\%, and 69\%, respectively; $p$ $<.001)$. Otherwise, probands were similar on all other demographic characteristics including social class, education, race, religion, and home environment (i.e., whom they live with) (data not shown).

\section{$D S M-I I I-R$ Diagnoses of Offspring}

Table 1 shows the rates of DSM-III-R diagnoses of the interviewed offspring by proband diagnosis. When compared with the offspring of never mentally ill probands, the offspring of probands with early-onset MDD had significantly higher rates of MDD, dysthymia, any anxiety disorder, and panic spectrum disorders (i.e., panic disorder, near panic, panic attacks, or separation anxiety). Offspring of probands who had panic with MDD had higher rates of separation anxiety and panic spectrum disorders and had more suicide attempts than offspring of never mentally ill probands (Table 1).

Of the 16 offspring with panic symptoms, 4 met criteria for separation anxiety. Ten offspring (of 16) reported panic symptoms before the age of 13 years. Five offspring reported spontaneous panic attacks before the age of 13 years. Sixty percent of those offspring 
TABLE 1

Best Estimate DSM-III-R Diagnoses in Offspring by Proband Group: Interviewed Only $(n=145)$

\begin{tabular}{|c|c|c|c|c|c|}
\hline $\begin{array}{l}D S M-I I I-R \\
\text { Diagnoses }\end{array}$ & $\begin{array}{c}\text { Never } \\
\text { Mentally Ill } \\
(1) \\
(n=36)\end{array}$ & $\begin{array}{c}\text { Early-Onset }^{a} \\
\text { MDD } \\
(2) \\
(n=32)\end{array}$ & $\begin{array}{c}\text { Panic } \\
\text { without MDD } \\
(3) \\
(n=17)\end{array}$ & $\begin{array}{c}\text { Panic } \\
\text { with MDD } \\
\quad(4) \\
(n=60)\end{array}$ & Comparison \\
\hline MDD & $5 \quad(13.8)$ & $10(31.2)$ & $(5.8)$ & $7(11.6)^{*}$ & 1 vs. $2 \ddagger$ \\
\hline Dysthymia & $2 \quad(5.5)$ & $5(15.6)$ & $1 \quad(5.8)$ & $6(10.0)$ & 1 vs. $2 \dagger$ \\
\hline Age at onset of $\mathrm{MDD}$ & $15.4(2.6)$ & $12.9(5.1)$ & $11.0^{6}$ & $14.0(4.8)$ & \\
\hline Any anxiety & $7(19.4)$ & $11(34.3)$ & $4(23.5)$ & $17(28.3)$ & 1 vs. $2 \dagger$ \\
\hline Panic disorder & $0 \quad(0.0)$ & $\begin{array}{ll}0 & (0.0)\end{array}$ & $0 \quad(0.0)$ & $1 \quad(1.6)$ & \\
\hline Any panic & $3 \quad(8.3)$ & $4 \quad(12.5)$ & $(0.0)$ & $9(15.0)$ & \\
\hline Near panic & $1 \quad(2.7)$ & $1 \quad(3.1)$ & $(0.0)$ & $3 \quad(5.0)$ & \\
\hline Spontaneous panic & $0 \quad(0.0)$ & $2 \quad(6.2)$ & $(0.0)$ & $5 \quad(8.3)$ & \\
\hline Situational panic & $2 \quad(5.5)$ & $2 \quad(6.2)$ & $0 \quad(0.0)$ & $4 \quad(6.6)$ & \\
\hline Panic spectrum & $4(11.1)$ & $7(21.8)$ & $2(11.7)$ & $15(25.0)$ & 1 vs. $2 \dagger 4 \ddagger$ \\
\hline Separation anxiety & $1 \quad(2.7)$ & $4 \quad(12.5)$ & $2(11.7)$ & $9(15.0)$ & 1 vs. $4 \$$ \\
\hline Any phobia & $5(13.8)$ & $7(21.8)$ & $2(11.7)$ & $9(15.0)$ & \\
\hline Simple & $2 \quad(5.5)$ & $3 \quad(9.3)$ & $1 \quad(5.8)$ & $2 \quad(3.3)$ & \\
\hline Social & $4(11.1)$ & $5(15.6)$ & $(5.8)$ & $7(11.6)$ & \\
\hline Agoraphobia & $0 \quad(0.0)$ & $0 \quad(0.0)$ & $(0.0)$ & $0 \quad(0.0)$ & \\
\hline Overanxious & $0 \quad(0.0)$ & $\begin{array}{ll}0 & (0.0)\end{array}$ & $0 \quad(0.0)$ & $1 \quad(1.6)$ & \\
\hline $\mathrm{OCD}$ & $\begin{array}{ll}0 & (0.0)\end{array}$ & $\begin{array}{ll}0 & (0.0)\end{array}$ & $0 \quad(0.0)$ & $0 \quad(0.0)$ & \\
\hline Age at onset of anxiety & $8.0(5.4)$ & $7.8(2.5)$ & $5.2(1.8)$ & $9.3(5.9)$ & \\
\hline $\begin{array}{l}\text { Age at onset of panic } \\
\text { symptoms } \\
\text { Adjustment disorder }\end{array}$ & $13.0(2.6)$ & $11.0(5.7)$ & & $15.1(5.0)$ & \\
\hline Anxiety & $\begin{array}{ll}0 & (0.0)\end{array}$ & $0 \quad(0.0)$ & $(0.0)$ & (3.3) & \\
\hline Depression & $1 \quad(2.7)$ & $3 \quad(9.3)$ & $(0.0)$ & $(5.0)$ & \\
\hline $\mathrm{MDD}$ and any panic & $1 \quad(2.7)$ & $4(12.5)$ & $(0.0)$ & $(5.0)$ & \\
\hline Any panic only & $2 \quad(5.5)$ & $0 \quad(0.0)$ & $(0.0)$ & $6(10.0)$ & \\
\hline MDD only & $4(11.1)$ & $6(18.7)$ & $1 \quad(5.8)$ & $4 \quad(6.6)$ & \\
\hline Neither & $29(80.5)$ & $22(68.7)$ & $16(94.1)$ & $47 \quad(78.3)$ & \\
\hline Suicide attempts & $\begin{array}{ll}0 & (0.0)\end{array}$ & $1 \quad(3.2)$ & $1 \quad(5.8)$ & $6(10.3)$ & 1 vs. $4 \$$ \\
\hline
\end{tabular}

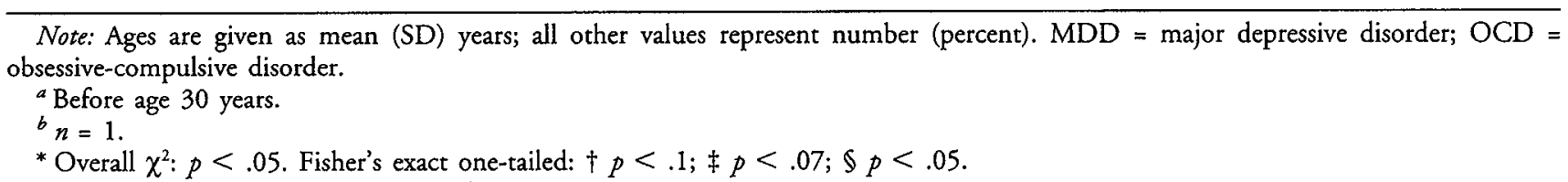

who reported near panic attacks reported full-blown spontaneous panic attacks, compared with $2 \%$ of the offspring without near panic attacks $(p<.001)$ (data not shown).

\section{Social Functioning and Marital Status}

There was considerable variability in social functioning and marital status within the ill probands. Probands with panic with MDD tended to report significantly poorer current social functioning (as measured by the Social Adjustment Scale) than probands from the earlyonset MDD and the panic without MDD groups. Probands with early-onset MDD or panic with MDD reported significantly higher rates of divorce and more impairment (as measured by the GAS) than probands from the never mentally ill or panic without MDD group. Probands from all ill proband groups had significantly poorer marital adjustment (as measured by the DAS) than probands from the never mentally ill proband group. Probands with early-onset MDD and panic with and without MDD were more likely to report higher scores on the Adaptability subscale of the FACES, indicating a more chaotic family environment than reported by never mentally ill probands (Table 2 ). A high adaptability score in this sample was significantly associated with divorce and alcohol abuse and/or dependence in the coparent. Forty-four percent of the families reporting high adaptability, compared with $17 \%$ of the families reporting low adaptability, reported a history of divorce $(p<.01)$. Thirty-two percent of the families 
TABLE 2

Social Adjustment, Marital Adjustment, and Divorce in Children by Proband Diagnosis ( $n=82$ Probands and 145 Interviewed Children)

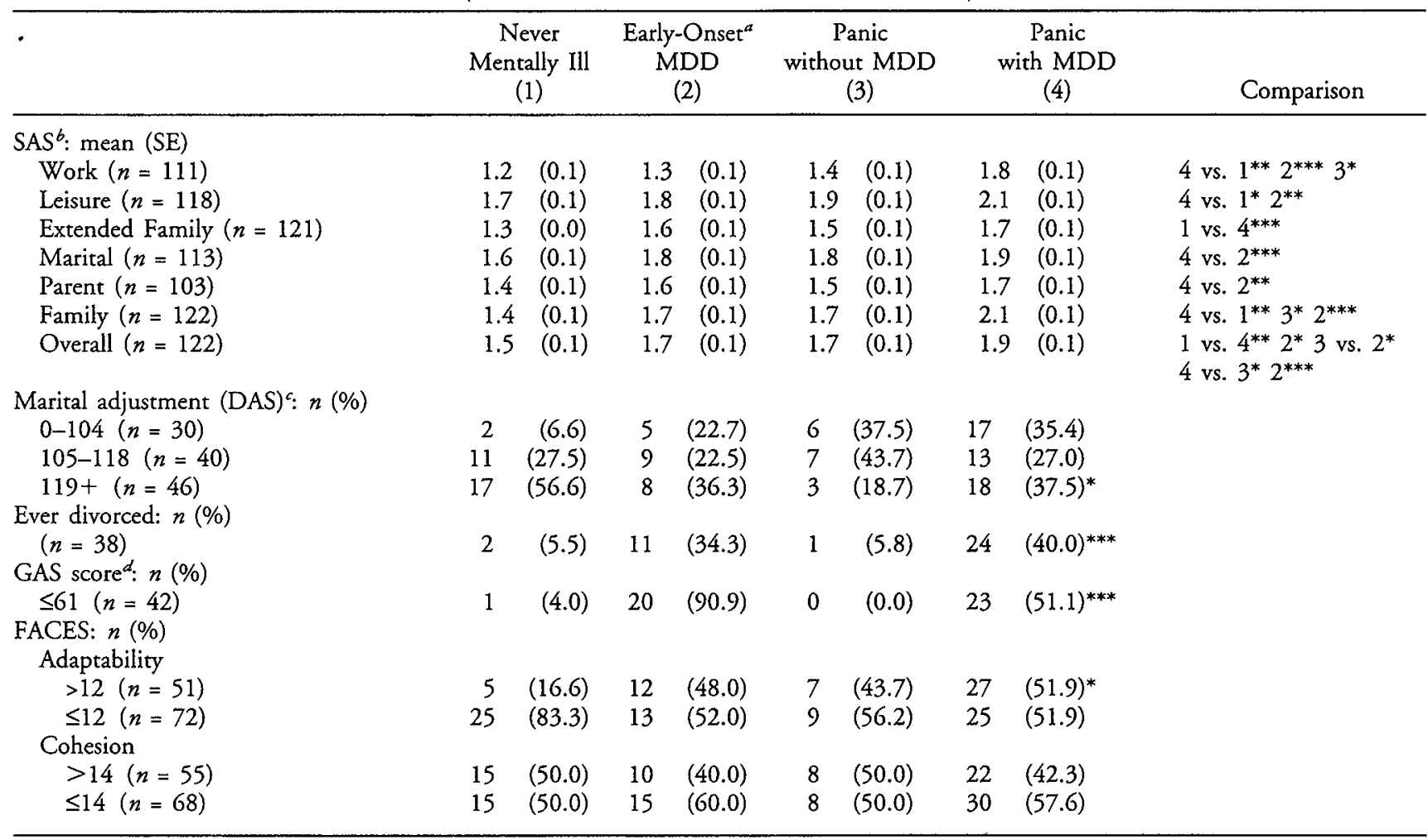

Note: $\mathrm{MDD}=$ major depressive disorder; SAS = Social Adjustment Scale; DAS = Dyadic Adjustment Scale; GAS = Global Assessment Scale; FACES = Family Adaptability and Cohesion Scale.

${ }^{a}$ Before age 30 years.

${ }^{b}$ Higher scores mean poor social adjustment.

'Lower scores mean poor marital adjustment.

${ }^{d}$ Lower scores mean impaired functioning.

${ }^{*} p<.05{ }^{* *} p<.01 ;{ }^{* * *} p<.001$.

with a high adaptability score had coparents with alcohol abuse and/or dependence compared with $17 \%$ of the families with low adaptability scores $(p=.05)$.

\section{DSM-III-R Diagnoses of Proband and Coparent}

There was also variability in comorbidity and coparent diagnoses within the ill probands. Probands with panic and MDD had significantly higher rates of comorbid simple phobia than did probands with earlyonset major depression or panic without MDD (29\%, $12 \%$, and $17 \%$, respectively; $p<.05$ ). Coparents of probands with panic with MDD and panic without MDD had significantly higher rates of any substance abuse than coparents of never mentally ill or earlyonset MDD probands $(32 \%, 46 \%, 6 \%$, and $23 \%$, respectively; $p<.01$ ). In particular, coparents of probands with panic without MDD had higher rates of alcohol abuse than coparents of probands with panic with $\mathrm{MDD}$, early-onset $\mathrm{MDD}$, and never mentally ill probands $(42 \%, 17 \%, 13 \%$, and $6 \%$, respectively; $p$ $<.01)$. Coparents of probands with panic with MDD had significantly more impaired functioning (as measured by the GAS) than coparents of early-onset MDD, panic without MDD, and never mentally ill probands $(27 \%, 9 \%, 17 \%$, and $4 \%$, respectively; $p=.06)$.

\section{Multivariate Analyses}

Table 3 presents the results of the multivariate analyses which take into account these differences in probands in explaining diagnoses in offspring.

Depression in Offspring. Offspring of probands with recurrent (two or more episodes), early-onset $M D D$ had a threefold increase in risk for DSM-III-R MDD compared with offspring of the never mentally ill 
TABLE 3

Proportional Hazards Model Assessing the Association of Proband Diagnosis on Offspring's Diagnosis: Interviewed Offspring Only

\begin{tabular}{|c|c|}
\hline$D S M-I I I-R$ Diagnoses & Risk Ratio $(95 \% \mathrm{CI}) / \boldsymbol{\beta}(\mathrm{SE})$ \\
\hline \multicolumn{2}{|l|}{ Major depression } \\
\hline Early-onset MDD (recurrent) & $3.00(0.93,9.66) \S$ \\
\hline Early-onset MDD (nonrecurrent) & $1.80(0.39,8.24)$ \\
\hline Panic without MDD & $0.41(0.04,3.65)$ \\
\hline Panic with MDD & $0.48(0.13,1.71)$ \\
\hline Sex & $2.98(1.20,7.42)^{*}$ \\
\hline Age & $-0.10(0.06)$ \\
\hline Alcohol abuse/dependence (coparent) & $3.48(1.24,9.77)^{*}$ \\
\hline \multicolumn{2}{|l|}{ Dysthymia } \\
\hline Early-onset MDD & $2.02(0.21,19.52)$ \\
\hline Panic with MDD & $1.06(0.11,10.01)$ \\
\hline Panic without MDD & $0.93(0.05,15.53)$ \\
\hline Sex & $1.57(0.46,5.30)$ \\
\hline Age & $-0.07(0.08)$ \\
\hline High adaptability & $11.90(1.41,100.35)^{*}$ \\
\hline \multicolumn{2}{|l|}{ Any anxiety } \\
\hline Early-onset MDD (recurrent) & $2.54(0.93,6.94) \S$ \\
\hline Early-onset MDD (nonrecurrent) & $0.63(0.13,3.12)$ \\
\hline Panic with MDD & $1.08(0.42,2.73)$ \\
\hline Panic without MDD & $1.13(0.33,3.90)$ \\
\hline Sex & $2.30(1.18,4.48)^{*}$ \\
\hline Age & $-0.04(0.03)$ \\
\hline GAS <61 (coparent) & $2.17(1.02,4.61)^{*}$ \\
\hline \multicolumn{2}{|l|}{ Panic spectrum } \\
\hline Early-onset MDD (recurrent) & $4.54(0.44,46.87)$ \\
\hline Early-onset MDD (nonrecurrent) & $6.17(0.32,117.17)$ \\
\hline Panic with MDD & $4.20(0.50,34.77)$ \\
\hline Panic without MDD & $1.67(0.10,27.37)$ \\
\hline Sex & $4.40(1.34,14.46)^{*}$ \\
\hline Age & $-0.09(0.07)$ \\
\hline High adaptability & $4.69(1.14,19.19)^{*}$ \\
\hline
\end{tabular}

Note $\mathrm{MDD}=$ major depressive disorder; GAS = Global Assessment Scale; $\mathrm{CI}=$ confidence interval. $\$ p=.05{ }^{*} p<.05 ;{ }^{* *} p<.01$; age of offspring-continuous- $\beta$ reported for age.

probands (relative risk $[R R]=3.00 ; p=.05$ ). Females had approximately triple the risk for MDD compared with males $(\mathrm{RR}=2.98 ; p<.05)$. Finally, offspring of coparents who met criteria for alcohol abuse were also at significantly increased risk compared with offspring of coparents without alcohol abuse $(\mathrm{RR}=3.48 ; p<.05)$. Alcohol abuse in the coparent was only significantly associated with offspring MDD in the panic with MDD proband group. In the panic with MDD proband group, $28 \%$ of the offspring with coparents with alcohol abuse and/or dependence had MDD compared with $2 \%$ of the offspring whose parents did not report alcohol abuse and/or dependence $(p<.01)$. Controlling for alcohol abuse in the coparent diminished the magnitude of the association between proband recurrent and nonrecurrent early-onset MDD and MDD in the offspring.
The panic with MDD proband group was subdivided to examine whether early-onset MDD or recurrent MDD increased the risk for offspring MDD in that proband group. Panic with early-onset MDD and panic with recurrent MDD were not associated with an increase in risk for offspring MDD. Poor functioning on the Parent and Family subscales of the Social Adjustment Scale was associated with an increased risk for offspring MDD only in the normal proband group. However, proband current functioning as measured by the Social Adjustment Scale (i.e., poor functioning on the Family subscale) was significantly associated with the number of episodes of proband MDD. Probands with two episodes of MDD had poorer current functioning on the Family subscale than probands with one episode, and probands with three or more episodes had even worse functioning (Social Adjustment Scale 
means [SD]: one episode, 1.6 [0.52]; two episodes, 1.9 [0.48]; and three episodes, 2.39 [0.98]; $p<.001$ ). Because of the small number of offspring MDD cases in this subgroup who reported on the Social Adjustment Scale score, the significant correlation between current functioning and recurrent, early-onset MDD, and a more significant model $\chi^{2}$ for the model presented (Table 3), we felt that the model without Social Adjustment Scale scores better explained the data than the model containing Social Adjustment Scale scores.

After we controlled for age and sex of offspring, proband group status was not associated with an offspring diagnosis of dysthymia. Offspring with chaotic family environments (as indicated by a high adaptability score on the FACES) had a significant increase in risk for dysthymia compared with offspring from nonchaotic family environments (Table 3 ).

Anxiety in Offspring. Offspring of probands with recurrent early-onset MDD without panic had nearly a threefold increase in any anxiety disorder compared with never mentally ill probands $(R R=2.54 ; p=.05)$. Female offspring had approximately a twofold increase in risk for any anxiety disorder over males. Offspring of coparents with impaired functioning (as measured by the GAS) had significantly higher rates of any anxiety than offspring of coparents without impaired functioning.

After we controlled for age and sex of offspring, proband group status was not associated with panic spectrum disorders (i.e., panic disorder, near panic, spontaneous or situational panic attacks, separation anxiety). Recurrent early-onset MDD marginally increased the risk for panic spectrum disorders, but the association disappeared after we controlled for the presence of a chaotic family environment (as measured by a high adaptability score). Offspring from families with chaotic family environments had a significant increase in risk for panic spectrum disorders compared with offspring from nonchaotic environments. Female offspring were four times as likely to have panic spectrum disorders as males $(\mathrm{RR}=4.40 ; p<.05)$ (Table 3$)$.

\section{DISCUSSION}

The major findings were as follows:

1. Recurrent proband MDD increases the risk for offspring MDD.
2. Alcohol abuse in the coparent increases the risk for offspring MDD.

3. A chaotic family environment was an independent predictor of dysthymia after proband diagnosis was taken into account.

4. The risk for offspring "any anxiety" disorder was increased by proband recurrent early-onset MDD and by impaired functioning of the coparent.

5. The association between MDD in the proband and panic spectrum disorders in offspring was largely accounted for by chaotic family environment.

\section{Limitations}

The most obvious limitation of the sample is the comparatively low interview rate of the offspring and the fact that the interview rate varied across proband group. All differences in interviewed compared with noninterviewed probands would bias the results by artificially decreasing the rates in the interviewed sample differentially across proband group. This makes it more difficult to see associations than if we had a higher interview rate; that is, because of the low interview rate of offspring of panic probands without MDD, nothing definitive can be stated about that group. The size of the sample also did not permit us to test formally for existing and probable interactions. The original design of the study was to look at the association of MDD and panic in probands and their relatives. Probands, therefore (especially in the MDD-only and panic-only groups), were screened so that they did not have other primary diagnoses (e.g., alcohol/drug abuse) and certain comorbid diagnoses. Therefore, it was not possible to examine fully the effects of proband comorbidity, and hypotheses (other than the primary one) that can be tested are limited.

\section{Comparison with Other Studies}

Proband diagnoses of MDD and panic were highly associated with all of the family environmental factors (i.e., DAS, FACES, divorce) and with current social functioning as measured by the Social Adjustment Scale. Probands in the panic with MDD group tended to report poorer functioning, probably as a consequence of the extensive comorbidity in that group. While rates of family environmental factors were higher in the ill proband groups than in the never mentally ill proband group, the rates for all factors except divorce did not 
vary significantly between ill proband groups. This is consistent with our previous finding that probands with MDD had significantly higher rates of family environmental risk factors than probands without MDD (Fendrich et al., 1990). More specifically, our results replicate our previous findings of a significant association between MDD in the proband and divorce and poor marital adjustment.

Proband group was significantly associated with an increase in risk for offspring $\mathrm{MDD}$, anxiety disorders, dysthymia, and suicide attempts. However, once age and sex were controlled for in the proportional hazards model, only the recurrent form of early-onset MDD in the proband remained significantly associated with MDD and any anxiety disorder in the offspring. In fact, nonrecurrent, early-onset MDD did not significantly increase the risk for offspring psychiatric disorder.

Our finding that recurrent, early-onset MDD in the proband increased the risk for MDD in the offspring replicates our previous findings and the findings of many other studies (Orvaschel, 1990; Orvaschel et al., 1988; Warner et al., 1992; Weissman et al., 1987). It is of interest to note that when we looked at the panic probands with recurrent, early-onset $M D D$, there was no increased risk for offspring MDD. We found a trend for offspring of early-onset probands to have an earlier age at onset of MDD. However, the difference was not statistically significant, possibly because of the small sample size. Alcohol abuse in the coparent may mediate a small proportion of the increase in risk for offspring MDD due to proband recurrent, early-onset MDD and nonrecurrent, early-onset MDD as evidenced by the decrease in the magnitude of the risk ratio when added to the model. Alcohol abuse in the coparent increased the risk for offspring MDD, mainly in combination with panic and MDD in the proband. This may be due to the effect of nonrandom mating, or more likely it is due to the additive effects of having parents with multiple diagnoses. Similarly, Merikangas et al. (1988) found that offspring had higher rates of disorder if both parents had a disorder, and in an earlier study they found that assortative mating was associated with poor course and poor social adjustment in the proband, which may explain the increase in risk to offspring (Merikangas et al., 1983). Finally, poor current social functioning of the proband was associated with an increase in risk for MDD in offspring in the normal proband group. While the model including current social functioning was rejected because we felt that it was not possible to disentangle the effects of proband diagnosis on current functioning, the finding that social adjustment increased the risk for offspring MDD in the normal proband group is still noteworthy and requires further study.

Anxiety disorders present a different picture in this sample. An increase in risk for any anxiety disorder was associated with recurrent, early-onset MDD. When we examined panic spectrum disorders and controlled for high adaptability, recurrent, early-onset MDD lost significance, suggesting that chaotic family environment may act as a mediator in that association. We did find reasonably high rates of panic spectrum disorders (i.e., near panic, situational panic attacks, spontaneous panic attacks, separation anxiety, or panic disorder) in a relatively young sample. Nineteen percent $(28 / 145)$ of the interviewed sample of offspring reported panic spectrum disorders. However, only one case of DSM-III-R adolescent-onset panic disorder was reported. Ten of the offspring reported any panic (i.e., near panic, situational panic attacks, spontaneous panic attacks, or panic disorder) before the age of 13 , and $50 \%(5 / 10)$ reported spontaneous panic attacks before the age of 13 . This finding supports the contention that children are capable of reporting spontaneous panic attacks (Ballenger et al., 1989; Last and Strauss, 1989; Moreau et al., 1989).

Our findings regarding any anxiety disorder are consistent with work by Orvaschel et al. (1988), who found a nonsignificant trend for increased rates of anxiety disorder in offspring of patients with recurrent depression compared with normal controls. We did not replicate the findings of Biederman and colleagues' 1991 study, which showed that children of parents with panic and agoraphobia with or without MDD had higher rates of both anxiety and depressive disorders than normal controls (Biederman et al., 1991). This may have been because the panic probands in their study had primary agoraphobia. The association of anxiety disorders with high adaptability and with functioning of the spouse as measured by the GAS indicates the importance of environmental stressors in the etiology of earlier anxiety symptoms in children and indicates that what is inherited possibly is a vulnerability factor for disorder requiring an environmental stimulus.

Weissman et al. (1993) found an increase in risk for panic disorder only and panic with MDD in adult 
relatives of probands with panic disorder without MDD compared to relatives of never mentally ill probands; an increase in risk of panic with MDD, panic only, and early-onset MDD in relatives of probands with panic with MDD compared to relatives of never mentally ill probands; and, finally, an increased risk for early-onset MDD and panic with MDD in relatives of probands with early-onset MDD compared to relatives of never mentally ill probands. While similar analyses are not possible in this study because of low rates and zero cells, there are some similarities in the patterns (though not significant) found in rates of offspring MDD with any panic, any panic without MDD, and MDD without panic by comparable proband groups (Table 1). Offspring of probands with early-onset MDD tended to be at greater risk for panic with MDD than offspring of never mentally ill parents. Offspring of probands with panic with MDD tended to be at increased risk for panic with MDD, and panic without MDD, compared to offspring of never mentally ill probands.

Psychiatric diagnoses in a parent were not associated with an increase in risk for offspring dysthymia or substance abuse disorder. Dysthymia was only significantly associated with a high adaptability score. A high adaptability score (in this study) was associated with divorce in the family and a coparent diagnosis of alcohol abuse. The score reflects a sense of unpredictability and inconsistency in the family environment, and it seems logical that such an environment would be associated with low-level, persistent anxiety and depression symptoms.

Our findings that environmental factors play a role in the etiology of dysthymia are consistent other studies. Garrison et al. (1992) did not find an association with the FACES (a version different from that used for this study); however, they did find an increase in risk for dysthymia due to the offspring not living with both parents. Klein and coworkers have conducted numerous studies that examine and attempt to explain the nature of dysthymia (Klein, 1990; Klein et al., 1988a-c). They found that offspring of probands with unipolar, chronic, early-onset MDD were at increased risk for dysthymia (Klein et al., 1988a). However, they did not attempt to explain the mechanism for the increase in risk. It is interesting to note that Klein and coworkers' results parallel our bivariate results. Klein et al., in another study, found that patients with dysthymia reported significantly higher rates of chronic stress in major role areas (e.g., work, finances, health) than patients with major depression (Klein et al., 1988b). Zanarini et al. (1989), in a study of individuals with borderline personality disorder in which they use a dysthymic control group, found that $76 \%$ of dysthymic patients reported neglect by a primary caretaker. These results indicate that environment plays a major role in the etiology of dysthymia.

\section{Conclusion}

The increased risk of offspring psychiatric disorder in offspring of parents with psychiatric diagnoses has been clearly established. Further research into the mechanisms by which recurrent parental MDD increases the risk of offspring psychiatric disorder is warranted. These data support the hypothesis that, at least for a subset of psychiatric disorders, what may be inherited is a vulnerability to the disorder and that an environmental stressor (or stressors) may be required for manifestation of the disorder. Therefore, psychosocial interventions targeted at the environmental stressors could be effective in decreasing rates of disorder, especially with those children experiencing "near panic symptoms" and preventing them from developing fullblown panic attacks. Similar effectiveness of interventions could be true for decreasing rates of dysthymia in offspring. Based on these findings, clinicians treating the probands or adults should be alert to risk factors for the offspring. Early intervention in the family may act as a preventive measure against future onset of anxiety and dysthymia. Well-designed intervention studies intended to evaluate these hypotheses need to be done. Such research would facilitate the identification of possible intervention points.

\section{REFERENCES}

Ballenger JC, Carek DJ, Steele JJ, Cornish-McTighe D (1989), Three cases of panic disorder with agoraphobia in children. Am J Psychiatry 146:922-924

Bernstein GA, Borchardt CM (1991), Anxiety disorders of childhood and adolescence: a critical review. I Am Acad Child Adolesc Psychiatry 30:519-532

Biederman J, Rosenbaum JF, Bolduc EA, Faraone SV, Hirshfeld DR (1991), A high risk study of young children of parents with panic disorder and agoraphobia with and without comorbid major depression. Psychiatry Res 37:333-348

Biederman J, Rosenbaum JF, Hirshfeld D et al. (1990), Psychiatric correlates of behavioral inhibition in young children of parents with and without psychiatric disorders. Arch Gen Psychiatry 47:21-26 
Breslau N, Davis GC, Prabucki K (1987), Searching for evidence on the validity of generalized anxiety disorder: psychopathology in children of anxious mothers. Psychiatry Res 20:285-297

Casat CD (1988), Childhood anxiety disorders: a review of the possible relationship to adult panic disorder and agoraphobia. $\int$ Anxiety Disord 2:51-60

Cox DR (1972), Regression models and life tables. I R Stat Soc Series B, 34:187-220

Crowe RR, Noyes R, Pauls DL, Slymen D (1983), A family study of panic disorder. Arch Gen Psychiatry 40:1065-1069

Dunn LM, Dunn LM (1981), Peabody Picture Vocabulary Test-Revised. Circle Pines, MN: American Guidance Service

Endicott J, Spitzer RL, Fleiss J, Cohen J (1976), The Global Assessment Scale: a procedure for measuring overall severity of psychiatric disturbance. Arch Gen Psychiatry 33:766-771

Fendrich M, Warner V, Weissman MM (1990), Family risk factors, parental depression, and psychopathology in offspring. Dev Psychol 26:40-50

Fyer AJ, Mannuzza S, Martin LY et al. (1989), Reliability of anxiety assessment II. Symprom agreement. Arch Gen Psychiatry 46:1 102-1110

Garrison CZ, Addy CL, Jackson KL, McKeown RE, Waller JL (1992), Major depressive disorder and dysthymia in young adolescents. Am J Epidemiol 135:792-802

Hammen C, Adrian C, Hiroto D (1988), A longitudinal test of the attributional vulnerability model in children at risk for depression. $B r$ $J$ Clinical Psychol 27:37-46

Hammen C, Burge D, Burney E, Adrian C (1990a), Longitudinal study of diagnoses in children of women with unipolar and bipolar affective disorder. Arch Gen Psychiatry 47:1112-1117

Hammen C, Burge D, Stansbury K (1990b), Relationship of mother and child variables to child outcomes in a high-risk sample: a causal modeling analysis. Dev Psychol 26:24-30

Hammen C, Gordon D, Burge D, Adrian C, Jaenicke C, Hiroto D (1987), Maternal affective disorders, illness, and stress: risk for children's psychopathology. Am J Psychiatry 144:736-741

Hollingshead AB, Redlich FC (1958), Social Class and Mental Illness. New York: John Wiley \& Sons

Hopper JL, Judd FK, Derrick PL, Burrows GD (1987), A family study of panic disorder. Gen Epidemiol 4:33-41

John K, Gammon GD, Prusoff GA, Warner V (1987), The Social Adjustment Inventory for Children and Adolescents (SAICA): testing of a new semistructured interview. J Am Acad Child Adolesc Psychiatry 26:898-911

Keller MB, Beardslee WR, Dorer DJ, Lavori PW, Samuelson H, Klerman GR (1986), Impact of severity and chronicity of parental affective illness on adaptive functioning and psychopathology in children. Arch Gen Psychiatry 43:930-937

Keller MB, Beardslee W, Lavori PW, Wunder J, Drs DL, Samuelson H (1988), Course of major depression in non-referred adolescents: a retrospective study. J Affect Disord 15:235-243

Kendler KS, Kessler RC, Neale MC, Heath AC, Eaves LJ (1993), The prediction of major depression in women: toward an integrated etiologic model. Am J Psychiatry 150:1139-1148

Klein DN (1990), Depressive personality: reliability, validity, and relation to dysthymia. J Abnorm Psychol 99:412-421

Klein DN, Clark DC, Dansky L, Margolis E (1988a), Dysthymia in the offspring of parents with unipolar affective disorder. $J$ Abnorm Psychol 97:265-274

Klein DN, Taylor ET, Dickstein S, Harding K (1988b), The early-late onset distinction in DSM-III-R dysthymia. J Affect Disord 14:25-33

Klein DN, Taylor ET, Harding K, Dickstein S (1988c), Double depression and episodic major depression: demographic, clinical, familial, personality, and socioenvironmental characteristics and short-term outcome. Am J Psychiatry 145:1226-1231

Kovacs M, Gatsonis C, Paulauskas SL, Richards C (1989), Depressive disorders in childhood IV. A longitudinal study of comorbidity with and risk for anxiety disorders. Arch Gen Psychiatry 46:776-782

Kupfer DJ, Frank E, Carpenter LL, Neiswanger K (1989), Family history in recurrent depression. $\int$ Affect Disord 17:113-119
Last CG, Hersen M, Kazdin AE, Francis G, Grubb HJ (1987a), Psychiatric illness in the mothers of anxious children. $A m J$ Psychiatry 144:1580-1583

Last CG, Hersen M, Kazdin A, Orvaschel H, Perrin S (1991), Anxiety disorders in children and their families. Arch Gen Psychiatry 48:928-934

Last CG, Phillips JE, Statfeld A (1987b), Childhood anxiety disorders in mothers and their children. Child Psychiatry Hum Dev 18:103-110

Last CG, Strauss CC (1989), Panic disorder in children and adolescents. $J$ Anxiety Disord 3:87-95

Leckman JF, Sholomskas D, Thompson WD, Belanger A, Weissman MM (1982), Best estimate of lifetime psychiatric diagnosis: a methodological study. Arch Gen Psychiatry 39:879-883

Lewinsohn PM, Roberts RE, Seeley JR, Rohde P, Gotlib IH, Hops H (1994), Adolescent psychopathology: II. Psychosocial risk factors for depression. I Abnorm Psychol 103:302-315

Mannuzza S, Fyer AJ, Klein DF, Endicott J (1986), Schedule for Affective Disorders and Schizophrenia-Lifetime Version (modified for the study of anxiety disorders): rationale and conceptual development. $J$ Psychiatr Res 20:317-325

Merikangas KR, Bromet EJ, Spiker DG (1983), Assortative mating, social adjustment and course of illness in primary affective disorder. Arch Gen Psychiatry 40:795-800

Merikangas KR, Weissman MM, Prusoff BA, John K (1988), Assortative mating and affective disorders: psychopathology in offspring. Psychiatry $51: 48-57$

Moreau DL, Weissman MM, Warner V (1989), Panic disorder in children at high risk for depression. Am J Psychiatry 146:1059-1060

Mufson L, Weissman MM, Warner V (1992), Depression and anxiety in parents and children: a direct interview study. I Anxiety Disord 6:1-13

Olson DH, Sprenkle DH, Russell CS (1979), Circumplex model of marital and family systems: 1 . Cohesion and adaptability dimensions, family types and clinical applications. Fam Process 18:3-28

Orvaschel H (1990), Early onset psychiatric disorder in high risk children and increased family morbidity. I Am Acad Child Adolesc Psychiatry 29:184-188

Orvaschel H, Puig-Antich J, Chambers W, Tabrizi MA, Johnson R (1982), Retrospective assessment of prepubertal major depression with the Kiddie-SADS-E. I Am Acad Child Psychiatry 21:392-397

Orvaschel H, Walsh-Allis G, Ye W (1988), Psychopathology in children of parents with recurrent depression. I Abnorm Child Psychol 16:17-28

Puig-Antich J, Kaufman J, Ryan N et al. (1993), The psychosocial functioning and family environment of depressed adolescents. I Am Acad Child Adolesc Psychiatry 32:244-253

Reinherz HZ, Stewart-Berghauer MA, Pakiz B, Frost AK, Moeykens BA, Holmes WM (1989), The relationship of early risk and current mediators to depressive symptomatology in adolescence, $J$ Am Acad Child Adolesc Psychiatry 28:942-947

Rosenbaum JF, Biederman J, Gersten M et al. (1988), Behavioral inhibition in children of parents with panic disorder and agoraphobia. Arch Gen Psychiatry 45:463-470

Rutter M (1988), Longitudinal data in the study of causal processes: some uses and pirfalls in studies of psychosocial risk: the power of longitudinal data. In: Studies of Psychosocial Risks the Power of Longitudinal Data, Rutter M, ed. New York: Cambridge University Press, pp 1-28

SAS Institute Inc (1990), SAS/STAT User's Guide, Version 6, Fourth Edition, Vol 2. Cary, NC: SAS Institute Inc

Silverman WK, Cerny JA, Nelles WB, Burke AE (1988), Behavior problems in children of parents with anxiery disorders. $J$ Am Acad Child Adolesc Psychiatry 27:779-784

Spanier GB (1976), Measuring dyadic adjustment: new scales for assessing the quality of marriage and similar dyads. J Marriage Fam 38:15-28

Turner SM, Beidel DC, Costello A (1987), Psychopathology in the offspring of anxiety disorders patients. J Consult Clin Psychol 55:229-235

Van der Molen GM, Van den Hout MA, Van Dieren AC, Griez E (1989), Childhood separation anxiety and adult-onset panic disorders. I Anxiety Disord 3:97-106

Warner V, Weissman MM, Fendrich M, Wickramaratne P, Moreau DL (1992), The course of major depression in the offspring of depressed 
parents: incidence, recurrence, and recovery. Arch Gen Psychiatry 49:795-801

Weissman MM, Gammon GD, John K et al. (1987), Children of depressed parents: increased psychopathology and early onset major depression. Arch Gen Psychiatry 44:847-853

Weissman MM, John K, Merikangas KR et al. (1986), Depressed parents and their children: general health, social and psychiatric problems. $A m$ J Dis Child 140:801-805

Weissman MM, Leckman JF, Merikangas KR, Gammon GD, Prusoff BA (1984), Depression and anxiety disorders in parents and children: results from the Yale Family Study. Arch Gen Psychiatry 41:845-852

Weissman MM, Prusoff BA, Thompson WD (1978), Social adjustment by self-report in a community sample and in psychiatric outpatients. J Nerv Ment Dis 166:317-326

Weissman MM, Warner V, Wickramaratne P, Prusoff BA (1988), Early onset depression in parents and their children. $J$ Affect Disord 15:269-277

Weissman MM, Wickramaratne P, Adams P et al. (1993), The relationship berween panic disorder and major depression: a new family study. Arch Gen Psychiatry 50:767-780

Zanarini MC, Gunderson JG, Marino MF, Schwartz EO, Frankenburg FR (1989), Childhood experiences of borderline patients. Compr Psychiatry 30:18-25 